\title{
Effect of Hydrotalcite on Bromine Content in Oil Produced from the Pyrolysis of Acrylonitrile-Butadiene-Styrene Plastics
}

\author{
N. Morita, M. Nakayasu, T. Wajima, A. T. Saito, and H. Nakagome
}

\begin{abstract}
In this study, a method is presented to reduce the halogen concentration in the oil produced upon pyrolysis of acrylonitrile-butadiene-styrene (ABS) resins containing brominated flame retardants. More specifically, hydrotalcite was added to a predetermined amount of $\mathrm{ABS}$ in a glass reactor, and subjected to pyrolysis at $400{ }^{\circ} \mathrm{C}$ in nitrogen atmosphere. The bromine content in the product oil, residue, and gas released upon pyrolysis was analyzed. The main components of the product oil following pyrolysis of $\mathrm{ABS}$ in the absence of hydrotalcite additive were toluene, ethylbenzene, styrene, 1-bromomethyl-4-methylbenzene, phenol, $n$-butyl benzene, 1-methoxy-1-methylethyl benzene, and bromine compounds 2-bromophenol, 4-benzyloxy bromobenzene, 2,6 dibromophenol, and 2-bromotoluene. In contrast, the content of bromine in the product oil decreased when hydrotalcite was added to ABS. Moreover, negligible amounts of bromine were detected when the amount of added hydrotalcite was greater than $8 \mathrm{~g}$. The reduced content of bromine in the product oil was attributed to the efficient trapping of bromine in the hydrotalcite matrix (as determined by the content of bromine in the residue).
\end{abstract}

Index Terms-Acrylonitrile-Butadiene-Styrene halogen, hydrotalcite, pyrolysis.

(ABS),

\section{INTRODUCTION}

Electrical and electronic equipments (EEEs) are ubiquitous in our society, and have increasingly shorter lifespans as they become outdated and are replaced by newer models. EEEs constitute not only of computers, mobile phones, hair dryers, or refrigerators, but also cathode ray tubes [1]. These EEEs are subsequently considered as waste electrical and electronic equipments (WEEEs) at the end of their lifespan. Hence, the treatment of WEEEs has gained considerable importance [2]. In the European Union, the amount of WEEE generated per capita in 2005 was $17 \mathrm{~kg}$ that corresponds to an estimated 8.3-9.1 million tons of waste [3]. The EU has recently introduced legislation aimed to encourage reuse of WEEE and recycling to reduce the amount of WEEE sent to landfills and incineration [4]. These products contain many materials that can be recycled, such as glass or metal. However, the

Manuscript received June 15, 2015; revised October 17, 2015.

N. Morita is with the Department of Urban Environment Systems, Graduate School of Engineering, Chiba University, Japan (e-mail: Naoyuki_Morita@chiba-u.ne.jp).

M. Nakayasu is with the Tokyo Metropolitan Tama High School of Science and Technology, Japan (e-mail: Masami_1_Nakayasu@education.metro.tokyo.jp).

A. T. Saito, T. Wajima, and H. Nakagome are with Chiba University, Japan (e-mail: atsaito@r07.itscom.net, wajima@tu.chiba-u.ne.jp, nakagome@tu.chiba-u.ne.jp). remaining components that can constitute 15 types of plastics currently make the recycling process difficult [5]. Chemical recycling of plastics by thermal decomposition of WEEE has attracted interest as a promising technology. Upon thermal decomposition, the plastic polymer is converted into oil, residual carbon, and gases, which can be used as a chemical raw material and fuel [6]. Furthermore, there is a rich literature on basic research and chemical recycling of waste plastic based on thermal decomposition in the presence of a catalyst [7]-[18]. WEEE plastics typically consist of a flame retardant containing halogen compounds, and thus require special handling. Flame retardants can reduce the flammability of plastics, however, they represent a health hazard to humans owing to their toxic polybrominated compound components. Examples of such toxic components include polybrominated dibenzo-p-dioxins and polybrominated dibenzofurans [19]. The main plastic components in WEEE are acrylonitrile-butadiene-styrene (ABS) and high impact polystyrene (HIPS). Additionally, antimony trioxide is typically present as a synergist for the bromine-based flame retardant compounds. Is a technology for recycling the plastic of WEEE from hazards to health of these compounds research. In particular, extensive studies on the thermal decomposition of ABS [20]-[24], the use of catalyst [25]-[30], and the use of ammonia as a reducing agent [31], [32] have been carried out. As reported in the literature, the pyrolysis of brominated flame retardants-containing $\mathrm{ABS}$ in tubular reactors affords the release of bromine from the middle distillate and heavy oil component [23]. Moreover, studies on the thermal degradation of ABS using semi-batch reactors showed that the brominated flame retardant components could be converted into residual carbon [21]. Another study examined the thermal decomposition of tetrabromobisphenol A, a brominated flame retardant, in the presence of a zeolite catalyst (ZSM-5 or Y-type zeolite), whereby the latter catalyst was more effective in removing the bromine compound [27]. We previously reported that it was possible to reduce the content of bromine in the oil produced upon thermal decomposition of brominated polystyrene by using hydrotalcite (HT) additive [33]. HT is a layered double hydroxide consisting of a metal complex hydroxide comprising anionic species in the divalent $\mathrm{Mg}^{2+}$ and trivalent $\mathrm{Al}^{3+}$ host layers and interlayer of the guest layer [34], [35]. HT is the catalyst [36], [37] and gas removal [38] material for the [39], as ion exchanger [34], [35], [40], [41] has received increasing attention in recent years. High anion exchange capacity comparable to HT organic ion-exchange resins has 
received much attention and has been used as an adsorbent for the removal of various contaminants in aqueous solutions. The adsorption properties of inorganic anions such as sulfates, chromates, arsenates, selenate, borates, nitrates, fluorides, and phosphates have been studied [42]. The adsorption of anions onto HT is known to proceed via the formation of inter-layer outer sphere complexes upon an anion exchange reaction [43]. Additionally, HT has been generating interest as a catalyst in bio-diesel fuel production, whereby a noted increased yield from $62 \%$ to $77 \%$ has been observed in the presence of HT catalyst [44], [45]. The catalytic activity of HT has been further demonstrated in the aerobic oxidation of benzyl alcohol [46].

In this study, a method is presented to reduce the content of bromide in oil generated upon thermal decomposition of ABS at $400{ }^{\circ} \mathrm{C}$, whereby $\mathrm{HT}$ was employed as an additive during the pyrolysis process.

\section{EXPERIMENTAL}

\section{A. Materials}

ABS was obtained from Asahi Kasei Chemicals Corporation. A synthetic HT was used as an additive (DHT-4A; Kyowa Chemical Industry Co., Ltd.,).

\section{B. Experimental Apparatus and Procedures}

The experimental apparatus used in this study is shown in Fig. 1. A mixture of HT and ABS (20 g) were introduced into a glass reactor. To remove oxygen from the reactor, the latter was flushed with nitrogen gas at $50 \mathrm{~mL} / \mathrm{min}$ for $1 \mathrm{~h}$. Pyrolysis was then initiated. The temperature of the glass reactor where the sample resided was monitored using a thermocouple. The temperature of the reactor was increased to $400{ }^{\circ} \mathrm{C}$ at a heating rate of $5^{\circ} \mathrm{C} / \mathrm{min}$, after which it was allowed to cool naturally. The gases generated during pyrolysis were recovered in a recovery container as the product oil passed through the cooling condensation pipe. Non-condensable gases were collected in a gas pack via bubbling of an alkaline aqueous solution, a bromine alkaline generated gas bromide ions in the solution.

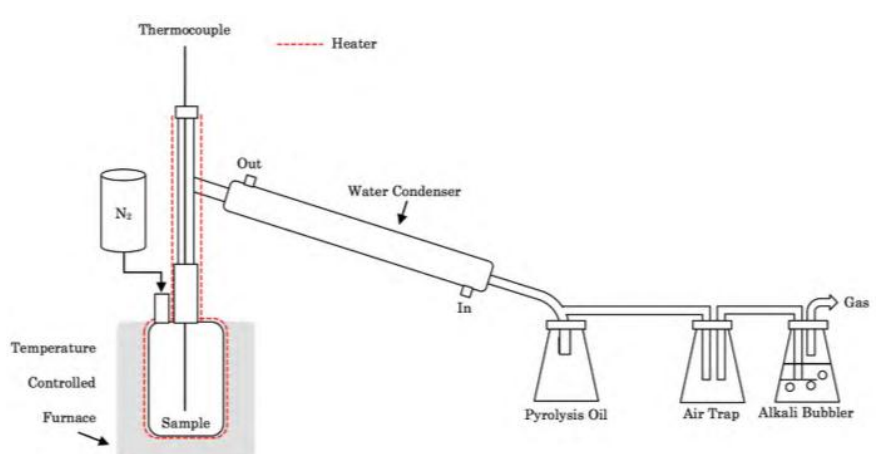

Fig. 1. Experimental apparatus.

\section{Analysis}

The product oil was diluted 100 times with hexane (Guaranteed Reagent grade, Wako Pure Chemical Industries), and analyzed by comparing the peaks obtained by gas chromatography-mass spectrometry (GC-MS) on a Shimadzu GCMS-QP2010 Ultra. The compounds were identified using a GC-MS spectral library. Pure helium was used as a carrier gas and a Rtx-1 column (inner diameter of $0.25 \mathrm{~mm}$ and film thickness of $0.25 \mu \mathrm{m}$ ) was used. For analysis, the temperature was maintained at $40^{\circ} \mathrm{C}$ for $30 \mathrm{~min}$, and then increased to $230{ }^{\circ} \mathrm{C}$ at a heating rate of $5{ }^{\circ} \mathrm{C} / \mathrm{min}$.

The bubbling alkaline aqueous solution was diluted to 100-fold with ultrapure water and subjected to ion chromatography on a Shimadzu ion chromatograph to determine the bromine concentration. A Shim-pack column $(150 \mathrm{~L} \times 4.6)$ and CDD-10Asp detector were used.

The structure of the residue (following pyrolysis) was examined by X-ray diffraction (XRD; D2 PHASER, Bruker $\mathrm{Xxx}$ ). The composition of the residue was examined by scanning electron microscopy (TM3030, Hitachi) coupled with energy-dispersive X-ray spectroscopy (BURUKER QUANTAX). Elemental distribution mapping of the surface of the sample residue following thermal decomposition was conducted. Energy-dispersive X-ray spectroscopy images were collected from five different samples areas, and provided quantitative determination of the bromine contents in these areas. The obtained values were averaged accordingly to determine the representative content of bromine.

Furthermore, assuming that the landfill .The residue obtained after pyrolysis was subjected to a bromine dissolution test. The residue was mixed with distilled water at a ratio of 3: 100 of 200 times / min, and the mixture was shaken for $2 \mathrm{~h}$. The supernatant liquid following centrifugation was subjected to ion chromatography to determine the content of bromine leached from the residue.

\section{RESULTS AND DISCUSSION}

\section{A. Product Oil}

The yield of the product oil obtained upon pyrolysis of ABS is shown in Fig. 2. As the results show, the yield of the product oil varied in the range of 35-45\% regardless of the amount of added HT (0-20 g).

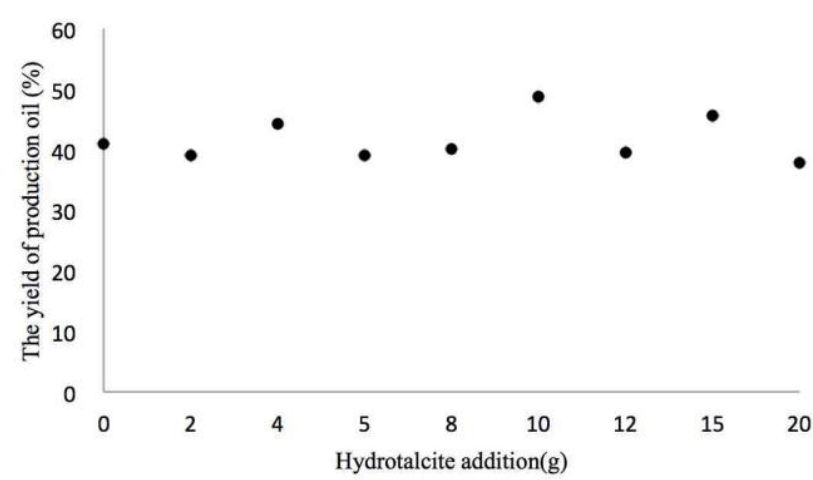

Fig. 2. Yield of product oil following pyrolysis of ABS in the presence of varying amounts of HT additive.

\section{B. Residue}

Table I lists the chemical components in the oil generated upon thermal decomposition of ABS in the presence of varying amounts of HT. Toluene, ethylbenzene, styrene, phenol, $n$-butyl benzene, and 1-methoxy-1-methylethylbenzene were detected along with 
bromine compounds 1-bromomethyl-4-methylbenzene, 2-bromophenol, 4-benzyloxy bromobenzene, 2,6-dibromophenol, and 2-bromotoluene upon thermal decomposition of ABS in the absence of HT additive. In contrast, the bromine compounds were not detected when the $\mathrm{HT}$ additive amount was greater than $8 \mathrm{~g}$.

TABLE I: COMPONENTS OF PRODUCT OIL OBTAINED USING VARYING AMOUNTS OF HT AdDITIVE

\begin{tabular}{|c|c|c|c|c|c|c|c|c|c|c|}
\hline \multirow{2}{*}{ Compound } & \multirow{2}{*}{ Formula } & \multicolumn{9}{|c|}{ Amount of hydrotalcite additive (g) } \\
\hline & & 0 & 2 & 4 & 5 & 8 & 10 & 12 & 15 & 20 \\
\hline Toluene & $\mathrm{C}_{7} \mathrm{H}_{8}$ & $\circ$ & ० & $\circ$ & ○ & $\circ$ & $\circ$ & $\circ$ & $\circ$ & ० \\
\hline Ethylbenzene & $\mathrm{C}_{8} \mathrm{H}_{10}$ & $\circ$ & $\circ$ & $\circ$ & $\circ$ & $\circ$ & $\circ$ & $\circ$ & $\circ$ & $\circ$ \\
\hline Styrene & $\mathrm{C}_{8} \mathrm{H}_{8}$ & $\circ$ & ० & $\circ$ & $\circ$ & $\circ$ & $\circ$ & $\circ$ & $\circ$ & $\circ$ \\
\hline 1-Bromomethyl-4-methylbenzene & $\mathrm{C}_{8} \mathrm{H}_{9} \mathrm{Br}$ & $\circ$ & ० & $\circ$ & ० & nd & nd & nd & nd & nd \\
\hline Phenol & $\mathrm{C}_{6} \mathrm{H}_{5} \mathrm{OH}$ & $\circ$ & $\circ$ & $\circ$ & $\circ$ & nd & nd & nd & nd & nd \\
\hline$n$-Butyl benzene & $\mathrm{C}_{10} \mathrm{H}_{14}$ & $\circ$ & ० & $\circ$ & $\circ$ & nd & nd & nd & nd & nd \\
\hline 1-Methoxy-1-methylethylbenzene & $\mathrm{C}_{10} \mathrm{H}_{14} \mathrm{O}$ & $\circ$ & $\circ$ & $\circ$ & $\circ$ & nd & nd & nd & nd & nd \\
\hline 2-Bromophenol & $\mathrm{C}_{6} \mathrm{H}_{5} \mathrm{BrO}$ & $\circ$ & $\circ$ & $\circ$ & $\circ$ & nd & nd & nd & nd & nd \\
\hline 4-Benzyloxy bromobenzene & $\mathrm{C}_{13} \mathrm{H}_{11} \mathrm{BrO}$ & $\circ$ & $\circ$ & $\circ$ & $\circ$ & nd & nd & nd & nd & nd \\
\hline 2-Bromotoluene & $\mathrm{C}_{7} \mathrm{H}_{7} \mathrm{Br}$ & ○ & ○ & $\circ$ & ○ & nd & nd & nd & nd & nd \\
\hline
\end{tabular}

o, detected; nd, not detected

Fig. 3 illustrates the amount of bromine in the product oil upon thermal decomposition of ABS in the presence of varying amounts of HT additive. As the results show, in the absence of HT additive, the amount of bromine determined was $100 \%$, which decreased upon addition of HT. Further increases to $>8 \mathrm{~g}$ resulted in negligible detectable amounts of bromine. Hence, the results reveal that the amount of bromine in the product oil can be considerably reduced to zero upon addition of HT (>8 g).

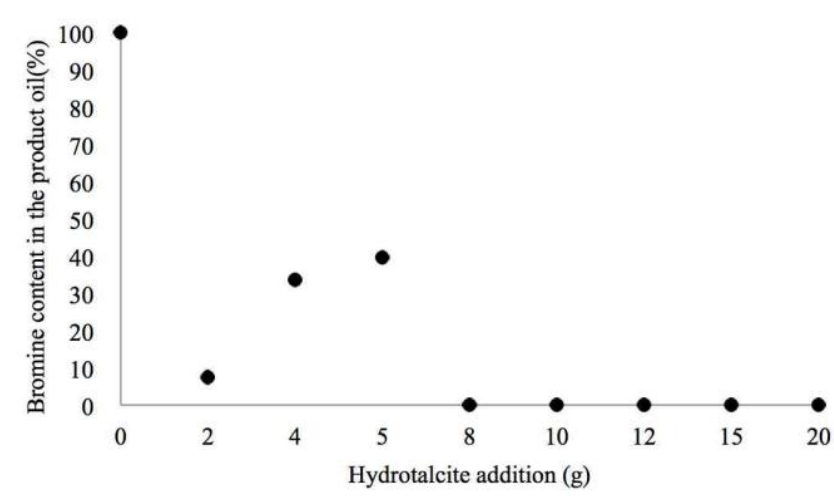

Fig. 3. Bromine content in the product oil following pyrolysis of ABS in the presence of varying amounts of HT additive.

The observation results of the residue by SEM are shown in Fig. 4. When the added amount of HT increased, the large particles and the small particles could be observed on the surface. The former can be interred to be Mg-Al oxides. And bromine can be interred to have been absorbed on the surface of the later.

The amount of bromine in the residue following pyrolysis is shown in Fig. 5. As the results show, the amount of bromine was $8.9 \%$ when HT was not added, and increased to $16 \%$ as the additive amount of HT increased $(2-5 \mathrm{~g})$. The amount of bromine was $23 \%$ when more than $8 \mathrm{~g}$ of HT was used. Thus, the results further confirmed that bromine was trapped within the residue upon addition of HT.
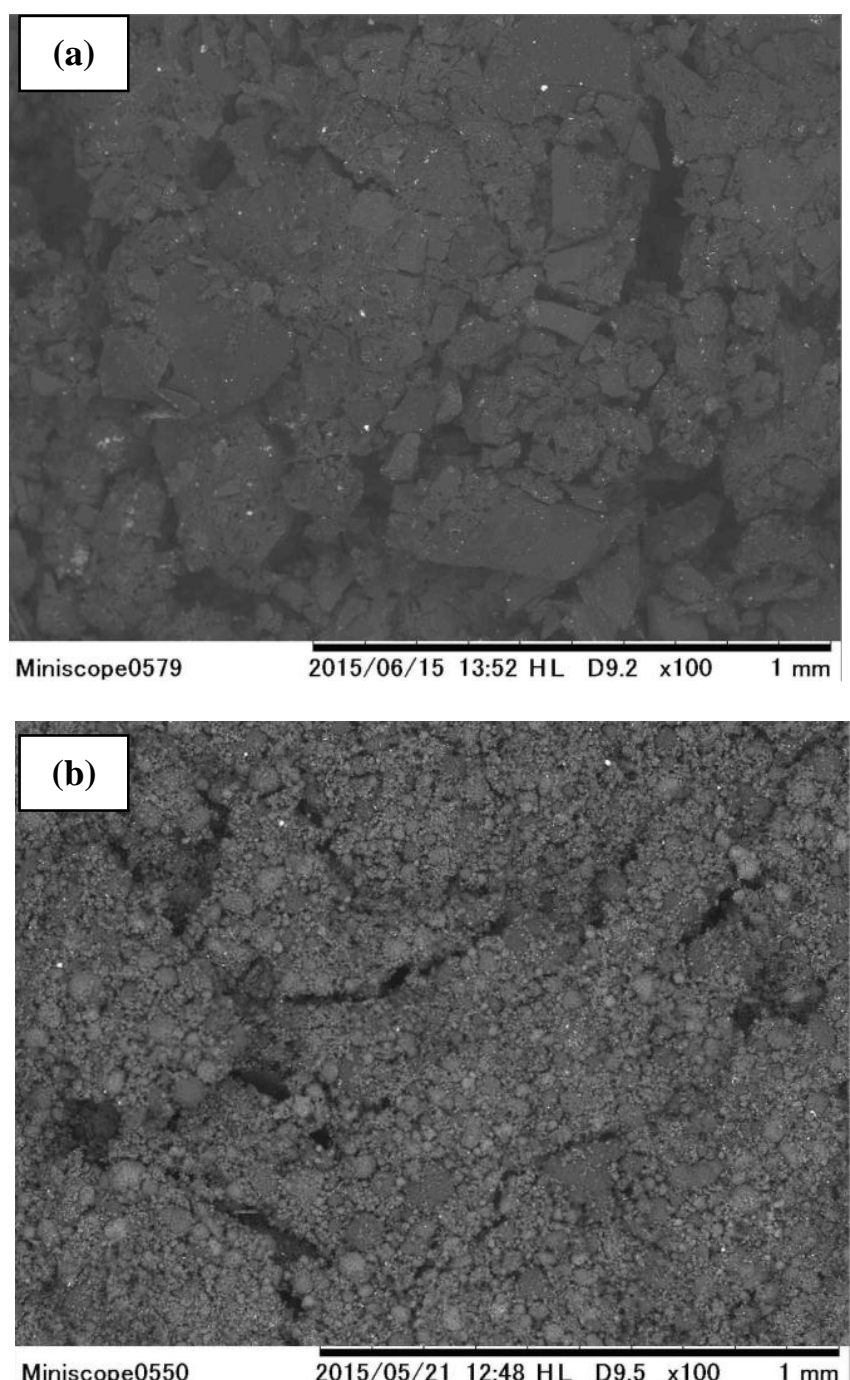

Fig. 4. Residue after pyrolysis of ABS (a) without HT and (b) with $10 \mathrm{~g}$ of HT.

The bromine dissolution test did not show leaching of bromine from the residue under all conditions examined. 
Therefore, we can conclude that bromine is strongly encapsulated into hydrotalcite.

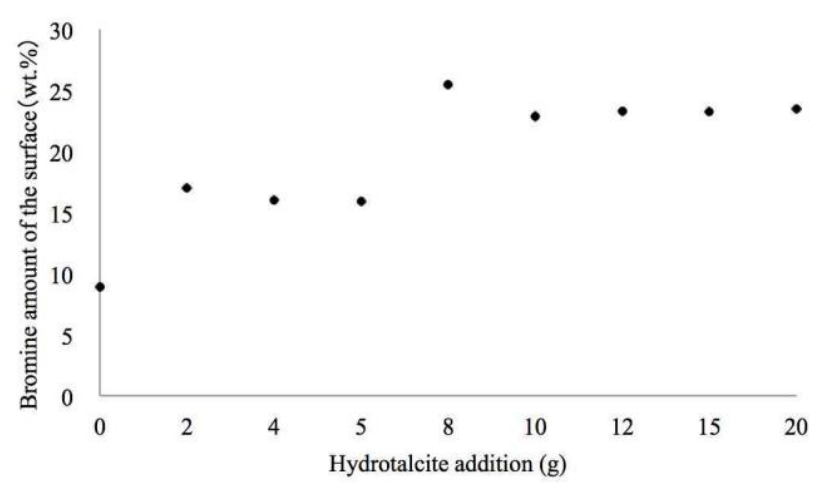

Fig. 5. Variations in the amount of bromine on the residue surface as a function of HT additive amount.

\section{Content of Bromine in Gas}

The gases generated upon pyrolysis of ABS were analyzed. Incidentally, the volume of gas generated by thermal decomposition was less than $1 \mathrm{~L}$ in all experiments conducted. The components of the water-insoluble gas include $\mathrm{H}_{2}, \mathrm{CH}_{4}$, and $\mathrm{CO}_{2} \cdot \mathrm{H}_{2}$ and $\mathrm{CH}_{4}$ were derived from the thermal decomposition of the plastic, whereas $\mathrm{CO}_{2}$ was derived from the combustion of hydrotalcite.

The content of bromine in the generated water-soluble gas is shown in Fig. 6. In the absence of HT additive, bromine was detected in the generated gas. In contrast, bromine was not detected when HT additive was used within the HT amounts studied. This result further confirmed that bromine was firmly trapped within the HT matrix and thus was not released in the gases produced during pyrolysis.

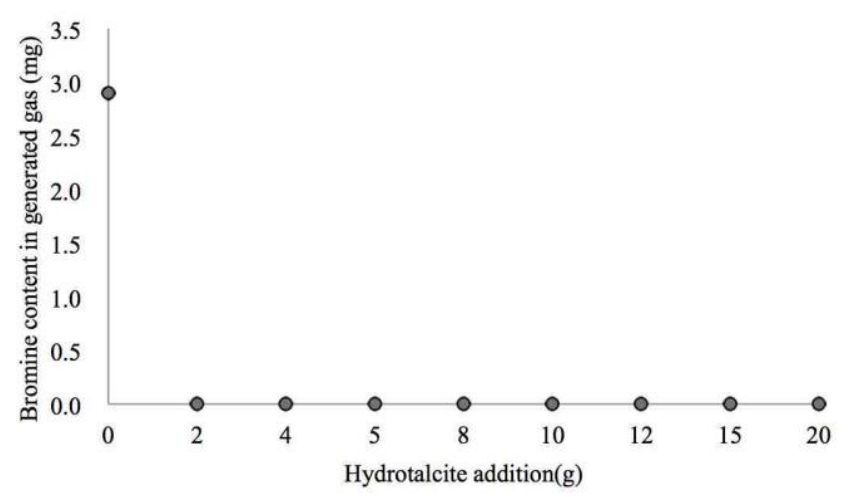

Fig. 6. Bromine content in the gas generated upon pyrolysis of ABS in the presence of HT at varying amounts.

\section{CONCLUSION}

In this study, the reduction of bromine content in the product oil obtained upon thermal decomposition of bromine-based plastic ABS was examined by introducing hydrotalcite additive. The results showed that the addition of an appropriate amount of hydrotalcite ( $>8 \mathrm{~g}$ ) to ABS sample $(20 \mathrm{~g})$ resulted in considerable reduction of the content of bromine (to zero) detected in the product oil.

The residue was added hydrotalcite is concentrated bromine, it is believed that the reason may be obtained a product oil of bromine does not contain. Furthermore, the bromine dissolution test confirmed that bromine was efficiently encapsulated within the hydrotalcite matrix, and thus did not leach in solution.

\section{ACKNOWLEDGMENT}

This work was supported by Mr. Katsuhiro Hosaka and Mr. Noriyuki Suzuki of Tokyo Metropolitan Tama High School of Science and Technology, Japan.

Can not be published by the co-author of the number of limited, Miss Momoka Suzuki, Miss Yuune Uchiyama, Miss Nana Terasoba and Miss Emi Ichinohe of Tokyo Metropolitan Tama high school of science and technology did a significant contribution in this study.

\section{REFERENCES}

[1] J. C. Acomb, M. A. Nahil, and P. T. Williams, "Thermal processing of plastics from waste electrical and electronic equipment for hydrogen production," Journal of Analytical and Applied Pyrolysis, vol. 103, pp. 320-327, 2013.

[2] S. Heart, "Environmental impacts and use of brominated flame retardants in electrical and electronic equipment," Environmentalist, vol. 28, pp. 348-357, 2008.

[3] United Nations University, "Review of Directive 2002/96 on Waste Electrical and Electronic Equipment (WEEE); final report," 2008.

[4] European Union, "EC, Directive 2002/96/EC Waste Electrical and Electronic Equipment," L27/34, 2003.

[5] G. Martinho, A. Pires, L. Saraiva, and R. Ribeiro, "Composition of plastics from waste electrical and electronic equipment (WEEE) by direct sampling," Waste Management, vol. 32, no. 6, p. 1213, 2012.

[6] T. Bhaskar, T. Matsui, J. Kaneko, M. A. Uddin, A. Muto, and Y. Sakata, "Novel calcium based sorbent $(\mathrm{Ca}-\mathrm{C})$ for the dehalogenation $(\mathrm{Br}, \mathrm{Cl})$ process during halogenated mixed plastic (PP/PE/PS/PVC and HIPS-Br) pyrolysis," Green Chem, vol. 4, pp. 372-375, 2002.

[7] G. Grause, J. Ishibashi, T. Kameda, T. Bhaskar, and T. Yoshioka, "Kinetic studies of the decomposition of flame retardant containing high-impact polystyrene," Polym Degrad Stab, vol. 95, pp. 1129-1137, 2010 .

[8] J. A. Onwudili, N. Insura, and P. T. Williams, "Composition of products from the pyrolysis of polyethylene and polystyrene in a closed batch reactor: Effects of temperature and residence time," J Anal Appl Pyrolysis, vol. 86, pp. 293-303, 2009.

[9] W. J. Hall and P. T. Williams, "Fast pyrolysis of halogenated plastics recovered from waste computers," Energy Fuel, vol. 20, pp. 1536-1549, 2006.

[10] T. Bhaskar, M. A. Uddin, K. Murai et al., "Comparison of thermal degradation products from real municipal waste plastic and model mixed plastics," J Anal Appl Pyrolysis, vol. 70, pp. 579-587, 2003.

[11] D. P. Serrano, J. Aguado, J. M. Escola, and E. Garagorri, "Performance of a continuous screw kiln reactor for the thermal and catalytic conversion of polyethylene-lubricating oil base mixtures," Appl Catal $B$, vol. 44, pp. 95-105, 2003.

[12] T. Bhask Ar, T. Matsui, and M. A. Uddin, "Effect of $\mathrm{Sb}_{2} \mathrm{O}_{3}$ in brominated heating impact polystyrene (HIPS-Br) on thermal degradation and debromination by iron oxide carbon composite catalyst (Fe-C)," Appl Catal B, vol. 43, pp. 229-241, 2003.

[13] K. Murata, Y. Hirano, Y. Sakata, and M. A. Uddin, "Basic study on a continuous flow reactor for thermal degradation of polymers," J Anal Appl Pyrolysis, vol. 65, pp. 71-90, 2002.

[14] M. Blazso', Z. Cze'ge'ny, and C. Csoma, "Pyrolysis and debromination of flame retarded polymers of electronic scrap studied by analytical pyrolysis," J Anal Appl Pyrolysis, vol. 64, pp. 249-261, 2002.

[15] H. Bockhorn, A. Hornung, U. Hornung, P. Jakobstro “er, and M. Kraus, "Dehydrochlorination of plastic mixtures," J Anal Appl Pyrolysis, vol. 49, pp. 97-106, 1999.

[16] M. Blazso' and E. Jakab, "Effect of metals, metal oxides, and carboxylates on the thermal decomposition processes of polyvinyl chloride," J Anal Appl Pyrolysis, vol. 49, pp. 125-143, 1999.

[17] R. Luijk, H. Haj, and L. Nelissen, "Formation of polybrominated dibenzofurans during extrusion of high-impact polystylene/decabromodiphenyl ether/antimony (III) oxide," Environ Sci Technol, vol. 26, pp. 2191-2198, 1992. 
[18] Y. Uemichi, Y. Makino, and T. Kanazuka, "Degradation of polyethylene to aromatic hydrocarbons over metal-supported activated carbon catalysts," J Anal Appl Pyrolysis, vol. 14, pp. 331-344, 1989.

[19] F. Barontini and V. Cozzani, "Formation of hydrogen bromide and organobrominated compounds in the thermal degradation of electronic boards," Journal of Analytical and Applied Pyrolysis, vol. 77, pp. 41-55, 2006.

[20] E. Jakab, Md. A. Uddin, T. Bhaskar, and Y. Sakata, "Thermal decomposition of flame-retarded high-impact polystyrene," Journal of Analytical and Applied Pyrolysis, vol. 68-69, pp. 83-99, 2003.

[21] T. Bhaskar, K. Murai, T. Matsui, M. A. Brebu, Md. A. Uddin, A. Muto Y. Sakata, and K. Murata, "Studies on thermal degradation of acrylonitrile-butadiene-styrene co- polymer (ABS-Br) containing brominated flame retardant," Journal of Analytical and Applied Pyrolysis, vol. 70, pp. 369-381, 2003.

[22] W. J. Hall and P. T. Williams, "Fast pyrolysis of halogenated plastics recovered from waste computers", Energy \& Fuels, vol. 20, pp. 1536-1549, 2006.

[23] N. Miskolczi, W. J. Hall, A. Angyal, L. Bartha, and P. T. Williams, "Production of oils with low organobromine content from the pyrolysis of flame retarded HIPS and ABS plastics," Journal of Analytical and Applied Pyrolysis, vol. 83, pp. 115-123, 2008.

[24] W. J. Hall and P. T. Williams, "Pyrolysis of brominated feedstock plastic in a fluidised bed reactor," Journal of Analytical and Applied Pyrolysis, vol. 77, pp. 75-82, 2006.

[25] T. Bhaskar, J. Kaneko, A. Muto, Y. Sakata, E. Jakab, T. Matsui, and Md. A. Uddin, "Effect of polyethylene terephthalate on the pyrolysis of brominated flame retardant containing high impact polystyrene and catalytic debromination of the liquid products," Journal of Analytical and Applied Pyrolysis, vol. 71, pp. 765-777, 2004.

[26] M. Brebu, T. Bhaskar, K. Murai, A. Muto, Y. Sakata, and Md. A. Uddin, "Removal of nitrogen, bromine, and chlorine from $\mathrm{PP} / \mathrm{PE} / \mathrm{PS} / \mathrm{PVC} / \mathrm{ABS}-\mathrm{Br}$ pyrolysis liquid products using $\mathrm{Fe}-$ and Ca-based catalysts," Polymer Degradation and Stability, vol. 87, pp. 225-230, 2005

[27] W. J. Hall and P. T. Williams, "Removal of organobromine compounds from the pyrolysis oils of flame retarded plastics using zeolite catalysts," Journal of Analytical and Applied Pyrolysis, vol. 81, pp. 139-147, 2008

[28] N. M. M. Mitan, M. Brebu, T. Bhaskar, A. Muto, and Y. Sakata, "Individual and simultaneous degradation of brominated high impact polystyrene and brominated acrylonitrile-butadiene-styrene and removal of heteroelements $(\mathrm{Br}, \mathrm{N}$, and $\mathrm{O})$ from degradation oil by multiphase catalytic systems," Journal of Material Cycles and Waste Management, vol. 9, pp. 56-61, 2007.

[29] M. Brebu, Md. A. Uddin, A. Muto, and Y. Sakata, "Catalytic degradation of acrylonitrile- butadiene-styrene into fuel oil 1. The effect of iron oxides on the distribution of nitrogen-containing compounds," Energy \& Fuels, vol. 15, pp. 559-564, 2001.

[30] Md. A. Uddin, T. Bhaskar, J. Kaneko, A. Muto, Y. Sakata, and T. Matsui, "Dehydrohalogenation during pyrolysis of brominated flame retardant containing high impact polystyrene (HIPS-Br) mixed with polyvinylchloride (PVC)," Fuel, vol. 81, pp. 1819-1825, 2002.

[31] A. Hornung, S. Donner, A. Balabanovich, and H. Seifert, "Polypropylene as a reductive agent for dehalogenation of brominated organic compounds," Journal of Cleaner Production, vol. 13, pp. 525-530, 2005.

[32] M. Brebu, E. Jakab, and Y. Sakata, "Effect of flame retardants and $\mathrm{Sb}_{2} \mathrm{O}_{3}$ synergist on the thermal decomposition of high-impact polystyrene and on its debromination by ammonia treatment," Journal of Analytical and Applied Pyrolysis, vol. 79, pp. 346-352, 2007.

[33] N. Morita, T. Wajima, and H. Nakagome "Reduction in Contents of Bromine Compounds in the Product Oil of Pyrolisis Using Synthetic Hydrotalcite," International Journal of Chemical Engineering and Applications, vol. 6, no. 4, pp. 262-266, 2015.

[34] T. Kwon, G. A. Tsigdinos, and T. J. Pinnavaia, "Pillaring of layered double hydroxides (LDH's) by polyoxometalate anions," J. Am. Chem. Soc., vol. 110, pp. 3653-3654, 1988.

[35] S. Miyata, "The syntheses of hydrotalcite-like compounds and their structures and physico-chemical properties $\mathrm{I}$ : The systems $\mathrm{Mg}^{2+}-\mathrm{Al}^{3+}-\mathrm{NO}_{3}^{-}, \mathrm{Mg}^{2+}-\mathrm{Al}^{3+}-\mathrm{Cl}^{-}, \mathrm{Mg}^{2+}-\mathrm{Al}^{3+}-\mathrm{ClO}_{4}^{-}, \mathrm{Ni}^{2+}-\mathrm{Al}^{3+}-\mathrm{Cl}^{-}$and $\mathrm{Zn}^{2+}-\mathrm{Al}^{3+}-\mathrm{Cl}^{-}$, , Clays Clay Miner, vol. 23, pp. 369-375, 1975.

[36] K. Ralla, U. Sohling, K. Suck, F. Sander, C. Kasper, F. Ruf, and T. Scheper, "Adsorption and separation of proteins by a synthetic hydrotalcite," Colloids and Surfaces B, Biointerfaces, vol. 87, pp. $217-225,2011$.
[37] E. Suzuki, M. Okamoto, and Y. Ono, "Catalysis by interlayer anions of a synthetic hydrotalcite-like mineral in a halide exchange between organic halides," Chem. Lett, vol. 18, pp. 1485-1486, 1989.

[38] K. J. Martin and T. J. Pinnavaia, "Layered double hydroxides as supported anionic reagents. Halide-ion reactivity in zinc chromium hexahydroxide halide hydrates $\left[\mathrm{Zn}_{2} \mathrm{Cr}(\mathrm{OH})_{6} \mathrm{X}_{\mathrm{nH}} \mathrm{nH}_{2} \mathrm{O}\right](\mathrm{X}=\mathrm{Cl}, \mathrm{I}),{ }^{\prime} \mathrm{J}$. Am. Chem. Soc., vol. 108, pp. 541-542, 1986.

[39] T. Kameda, N. Uchiyama, and T. Yoshioka, "Removal of $\mathrm{HCl}, \mathrm{SO}$ and NO by treatment of acid gas with Mg-Al oxide slurry,", Chemosphere, vol. 82, pp. 587-591, 2011.

[40] T. Kameda, M. Nakamura, and T. Yoshioka, "Removal of antimonate ions from an aqueous solution by anion exchange with magnesium-aluminum layered double hydroxide and the formation of a brandholzite-like structure," Journal of Environmental Science and Health, Part A, vol. 47, pp. 1146-1151, 2012.

[41] T. Kameda, K. Hoshi, and T. Yoshioka, "Uptake of $\mathrm{Sc}^{3+}$ and $\mathrm{La}^{3+}$ from aqueous solution using ethylenediaminetetraacetate-intercalated $\mathrm{CuAl}$ layered double hydroxide reconstructed from $\mathrm{CuAl}$ oxide," Solid State Sciences, vol. 13, pp. 366-371, 2011

[42] T. Kameda, N. Uchiyama, and T. Yoshiok, "Treatment of gaseous hydrogen chloride using $\mathrm{Mg}$ - $\mathrm{Al}$ layered double hydroxide intercalated with carbonate ion," Chemosphere, vol. 80, pp. 658-662, 2010.

[43] K. Morimoto, S. Anraku, J. Hoshino, T. Yoneda, and T. Sato, "Surface complexation reactions of inorganic anions on hydrotalcite-like compounds," Journal of Colloid and Interface Science, vol. 384, pp. 99-104, 2012.

[44] L. Deng and Z. Shi, "Synthesis and characterization of a novel $\mathrm{Mg}-\mathrm{Al}$ hydrotalcite-loaded kaolin clay and its adsorption properties for phosphate in aqueous solution," Journal of Alloys and Compounds, vol. 637 , pp. 188-196, 2015

[45] G. D. Yadav and P. A. Chandan, "A green process for glycerol valorization to glycerol carbonate over heterogeneous hydrotalcite catalyst," Catalysis Today, vol. 237, pp. 47-53, 2014

[46] D. Qiao, C. Xu, and J. Xu, "Aerobic oxidation of benzyl alcohol over $\mathrm{Co}_{3} \mathrm{O}_{4} /$ rehydrated hydrotalcite catalysts: The promotional effect of hydrotalcite support," Catalysis Communications, vol. 45, pp. 44-48, 2012.

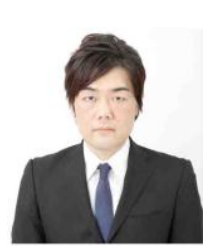

Naoyuki Morita was born in Japan 1977. He graduated from Chiba University, Japan, in 2011 and is now studying at the Department of Urban Environment System at Chiba University, Japan.

Masami Nakayasu was born in Japan 1976. She studied chemistry at Chuo University, and has been a teacher at Tokyo Metropolitan Tama High School of Science and Technology. Her specialty is environmental engineering.

Akiko Saito was born in Japan 1964. She is Researcher of the Toshiba Corporation. In addition, she has the research activities as Researcher of Chiba University. Her specialty is environmental engineering.

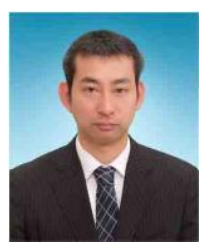

Takaaki Wajima was born in Japan 1976. He is an associate professor at Chiba University, Japan. He acquires a doctorate in Kyoto University. His specialty is energy engineering.

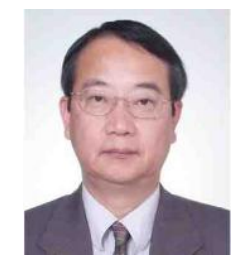

Hideki Nakagome was born in Japan 1951. He is professor at Chiba University, Japan. He acquires a doctorate in Tokyo University. His specialty is environmental engineering and mechanical engineering. 